\title{
BMJ Open Quality Multidisciplinary approach to improve the quality of below-knee plaster casting
}

\author{
John Teudar Williams, ${ }^{1}$ Marta Kedrzycki, ${ }^{2}$ Yathish Shenava ${ }^{2}$
}

To cite: Williams JT, Kedrzycki M, Shenava Y. Multidisciplinary approach to improve the quality of below-knee plaster casting.BMJ Open Quality 2018;7:e000284. doi:10.1136/ bmjoq-2017-000284

Received 13 December 2017 Revised 16 February 2018 Accepted 28 March 2018
Check for updates

${ }^{1}$ Trauma \& and Orthopaedic Department, Guy's and Saint Thomas' NHS Foundation Trust, London, UK

${ }^{2}$ Trauma and Orthopaedics, Queen Elizabeth Hospital, London, UK

Correspondence to Mr John Teudar Williams; john.t.williams@gstt.nhs.uk

\section{ABSTRACT}

Problem In our trauma unit, we noted a high rate of incorrectly applied below-knee casts for ankle fractures, in some cases requiring reapplication. This caused significant discomfort and inconvenience for patients and additional burden on plaster-room services. Our aim was to improve the quality of plaster casts and reduce the proportion that needed to be reapplied.

Methods Our criteria for plaster cast quality were based on the British Orthopaedic Association Casting Standards (2015) and included neutral (plantargrade) ankle position, adequacy of fracture reduction and rate of cast reapplication. Baseline data collection was performed over a 2-month period by two independent reviewers.

Interventions After distributing findings and presenting to relevant departments, practical casting sessions with orthopaedic technicians were arranged for the multidisciplinary team responsible for casting. This was later supplemented by new casting guidelines in clinical areas and available online. Postintervention data collection was performed over two separate cycles to assess the effect and permanence of intervention.

Results Data from the preintervention period $(n=29)$ showed median ankle position was $32^{\circ}$ plantarflexion (PF), with nine (31\%) inadequate reductions and six (20\%) backslabs reapplied. Following Plan-Do-Study-Act (PDSA) 1 , ankle position was significantly improved (median $25^{\circ}$ $\mathrm{PF})$, there were fewer inadequate reductions $(12 \% ; 2 / 17)$ and a lower rate of reapplication (0\%; 0/17). After PDSA 2 $(n=16)$, median ankle position was $21^{\circ} \mathrm{PF}$, there was one $(6 \%)$ inadequate reduction and two $(12 \%)$ reapplications of casts.

Conclusions Following implementation of plaster training sessions for accident and emergency and junior orthopaedic staff, in addition to publishing guidance and new protocol, there has been a sustained improvement in the quality of below-knee backslabs and fewer cast reapplications. These findings justify continuation and expansion of the current programme to include other commonly applied plaster casts.

\section{PROBLEM}

The bones of the ankle joint are among the most frequently fractured in adults, ${ }^{1}$ meaning that the application of below-knee plaster casts is a common occurrence in emergency departments (ED). Patients with uncomplicated stable fractures are generally discharged home in below-knee plaster and followed up in the fracture clinic. Unstable ankle fractures usually require inpatient admission and operative fixation.

On review of radiographs in our morning trauma meetings, it was noted that the quality of casting for ankle fractures was often unsatisfactory. Particularly, the ankle joint was frequently immobilised in an unstable plantarflexed position, or the fracture inadequately reduced. This problem was also highlighted by the orthopaedic plaster technicians who were required to reapply inadequate casts either on the wards or call patients back in from home the following day. In addition to causing discomfort and inconvenience to patients, it placed additional burden on already busy plaster room services.

The Queen Elizabeth Hospital serves a diverse population in South-East London with accident and emergency attendances approaching 100000 per annum. Our first task was to quantify and determine the extent of the problem in our unit and then aim to improve the quality of cast application. We proposed that we would thereby reduce the proportion requiring reapplication.

\section{BACKGROUND}

Guidance for the application of casts is discussed in detail in the British Orthopaedic Association Casting Standards, ${ }^{2}$ with the technique advocated by Gwozdz and Bakody recommended. ${ }^{3}$ The ankle joint should be adequately reduced and immobilised in a neutral position (ie, with the foot at $90^{\circ}$ to the leg).

To our knowledge, there is no literature describing quality improvement projects relating to plaster cast application, despite being such a common intervention. An audit published from the Manchester Royal Infirmary demonstrated that plaster casts for ankle fractures are generally applied incorrectly but did not include any interventions to improve outcomes. ${ }^{4}$

\section{BASELINE MEASUREMENT}

The outcome measures selected for study were (1) ankle 'neutrality' (ie, degree of 


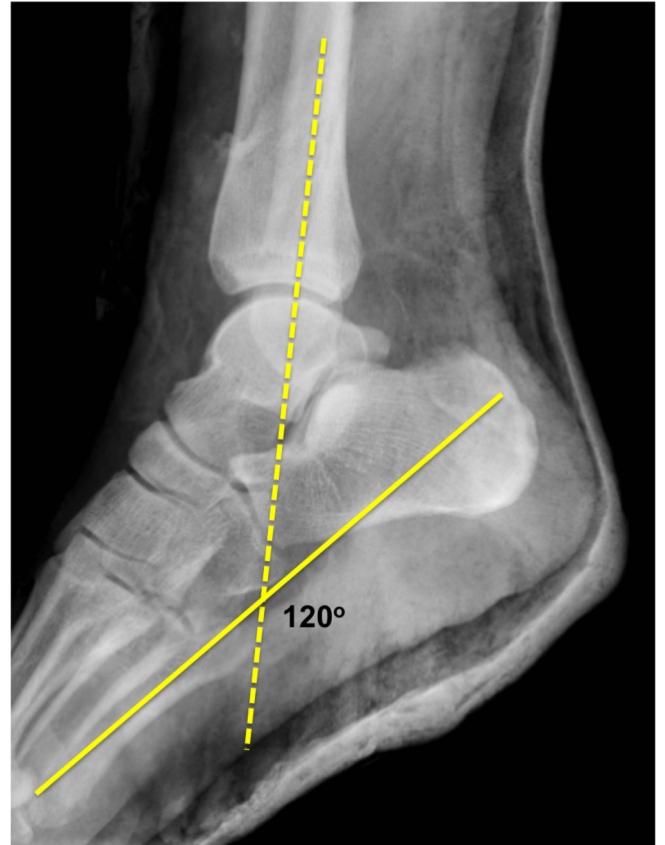

Figure 1 Method of measurement of ankle neutrality on lateral radiograph.

plantar/dorsiflexion from neutral), (2) the adequacy of tibio-talar reduction and (3) whether or not casts had to be reapplied. These measures were chosen because they are defined, reproducible and quantifiable, in addition to being referenced in published plaster application guidance. Furthermore, it is possible to determine these outcomes from radiographs taken immediately after plaster application. It was decided that two separate reviewers should collect data to ensure validity.

Data collection was planned over three separate periods: preintervention, cycle one and cycle two. A data collection tool was developed on Microsoft Excel by the lead author. All ankle radiographs during the study periods were reviewed and all newly fractured ankles in plaster casts were included. Non-acute ankle fractures seen in fracture clinic and casts applied after operative fixation were excluded.

Radiographs of the ankle in plaster were reviewed on IMPAX V.6.0 radiology software (Agfa-Gevaert, Mortsel, Belgium). Ankle neutrality was assessed on the lateral radiograph by measuring the axis of the fibula against the axis of the fifth metatarsal (figure 1). This method of measurement was adapted from a recent large multicentre study. ${ }^{5}$

\section{BASELINE RESULTS}

Baseline data collection was performed retrospectively over a 2-month period in November and December 2016. Twenty-nine cases were identified. The median ankle position was $32^{\circ}$ plantarflexion (PF); there were nine $(31 \%)$ inadequate reductions and six (20\%) casts required reapplication. Subsequent data collection was planned after
Lewisham and Greenwich W/HS

NHS Trust

\section{Below-knee back slabs in the QEH Emergency Department and UCC} FAO: T\&O doctors, ED staff, UCC staff
A recent audit of below-knee back slabs for ankle fractures applied in the QEH
Emergency Department + UCC:

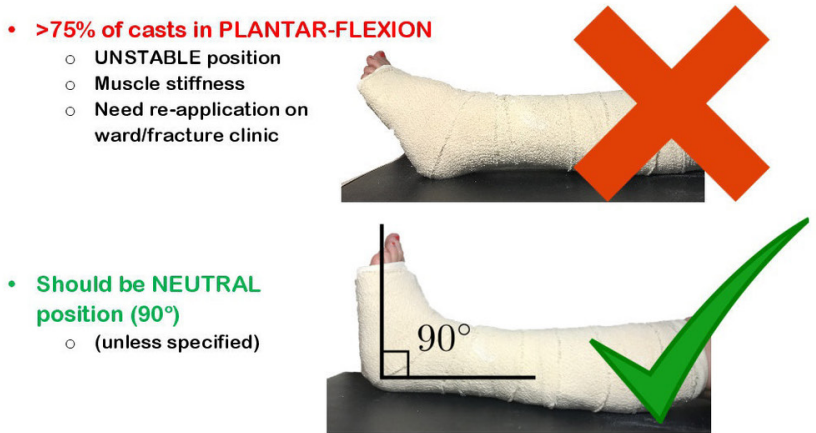

- $25 \%$ displaced fractures inadequately reduced.

Remember to obtain XRs before and aftercast application - if ankle position or fracture reduction in doubt seek senior advice before discharge or transfer to wards.

Refresher sessions available with the orthopaedic technicians

1. British Orthopaedic Association Casting Standards, November 2015

2. Drodz et al, Casting: below-knee back slabs, Emergency Nurse 17:7, 14-17, 2009

Figure 2 Information and guidance poster 1.

implementation of interventions during two separate month-long periods in April and June 2017.

\section{DESIGN}

The quality improvement project team consisted of two core surgical trainees, a senior orthopaedic technician and a consultant orthopaedic surgeon.

It was assumed there were a number of causes behind inadequate casting. First, a lack of awareness of correct technique among the variety of staff applying casts in the acute setting, which included ED doctors and nurses, orthopaedic junior doctors and urgent care nurse practitioners. Second, we assumed orthopaedic review of postplaster radiographs was not often sought and patients subsequently discharged with unsuitable casts. Third, due to the range of different departments applying casts, we assumed a lack of a unified approach and plaster cast policy.

Our initial baseline results were presented to the multidisciplinary trauma audit meeting and opinions sought. Subsequent meetings were held between members of the implementation team at monthly intervals. Initial interventions included distribution of best practice guidelines to the ED, urgent care centre (UCC) and orthopaedic staff. This was done via departmental presentations and staff email. Second, we planned a programme of practical 
Lewisham and Greenwich WHS

BELOW-KNEE BACKSLABS

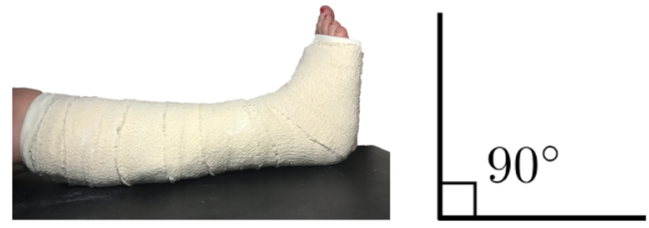

\section{ANKLE IN NEUTRAL POSITION}

(UNLESS OTHERWISE INSTRUCTED - CONTACT T\&O \#321 IF UNSURE)

OBTAIN CHECK-XRS TO ENSURE FRACTURE REDUCTION

Figure 3 Information and guidance poster 2.

training sessions led by the senior orthopaedic practitioners. Third, new guidance and information posters were created and affixed to the plaster trolleys and in relevant clinical areas (figures 2 and 3). We have used a driver diagram to demonstrate the root causes and our planned interventions (figure 4).

We anticipated problems in creating a coherent policy and training system between the ED, UCC and orthopaedic departments, due to separate management and organisational systems.

This project was designed to follow the Plan-DoStudy-Act (PDSA) format, with data collection and analysis planned over three separate periods. Our baseline data collection led us to plan and implement our initial interventions. Subsequent data analysis and feedback allowed us to adjust our interventions accordingly.

We used a run chart (figure 5) to demonstrate the change in ankle neutrality over time and in relation to our PDSA cycles, compared with the baseline median. Ankle neutrality was measured in degrees of plantar or dorsiflexion from the neutral $\left(0^{\circ}\right)$ position on lateral ankle radiographs.

Statistical analysis of ankle neutrality was performed using Student's t-test. Fisher's exact test was used to compare both the proportion of malreduced ankles and the proportion of casts reapplied, due to sparse data in these groups.

\section{STRATEGY}

During our first PDSA cycle, we disseminated results to the different departments (orthopaedic, emergency and UCG) via a combination of local presentations, emails and online information. Training sessions led by a senior plaster technician began to run for a rolling rota of ED staff and junior orthopaedic doctors.

Initial feedback from staff during this process was positive, although a potential issue identified was that agency staff and shift workers might miss staff briefings and/or the additional training. Performance data collected for this period was analysed and discussed among the implementation team.

During the second PDSA cycle, another method of distributing information and training among staff was devised in response to initial feedback. Guidance and performance data were published in poster format and placed in relevant staff areas. Simple and clear plaster application guidance was also affixed to all plaster cast trolleys in clinical areas (figures 2 and 3). During this cycle, plaster training sessions continued to run.

\section{RESULTS}

During the first PDSA cycle, 17 consecutive cases were identified over a month-long period. Median ankle neutrality significantly improved from the baseline

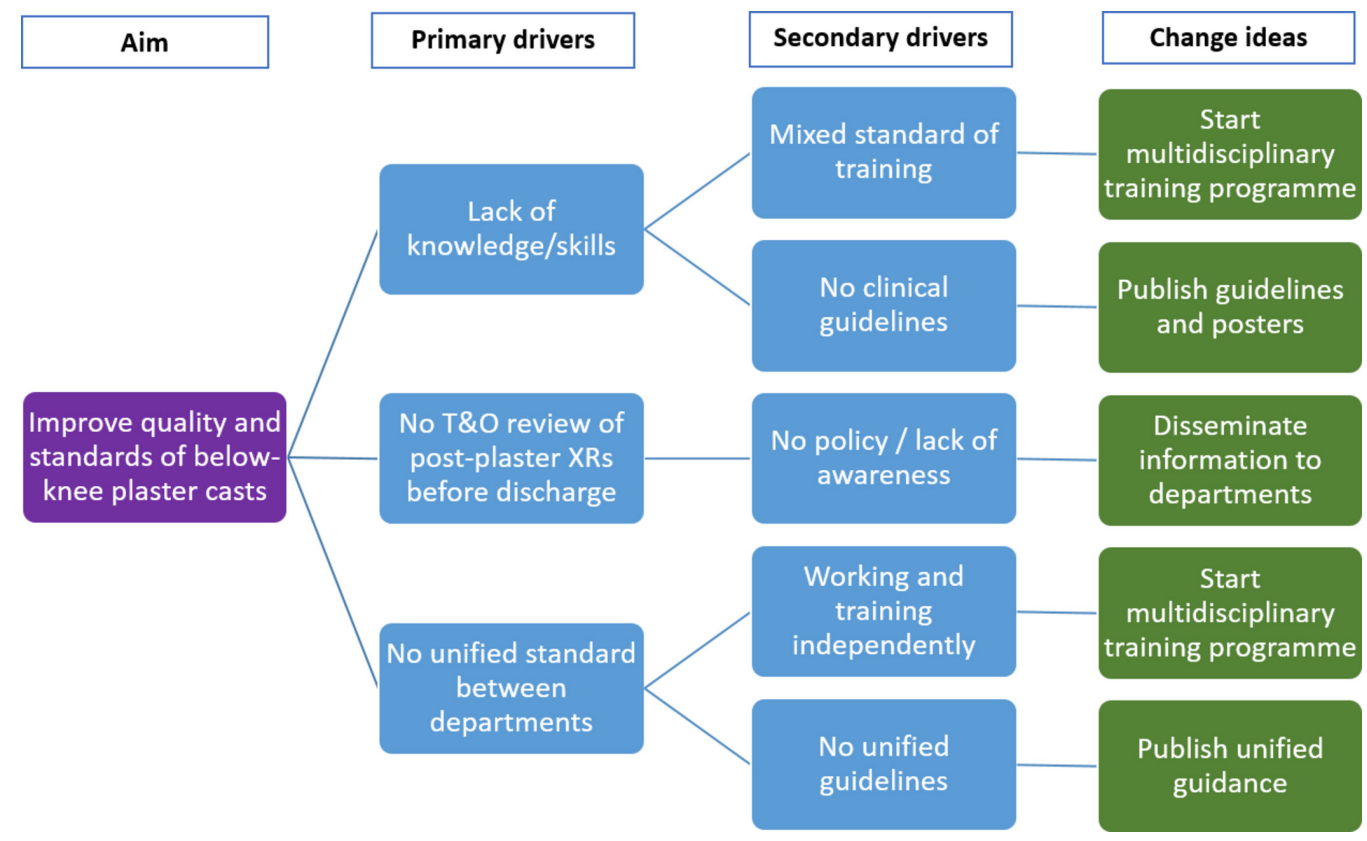

Figure 4 Driver diagram demonstrating root causes and respective interventions. 


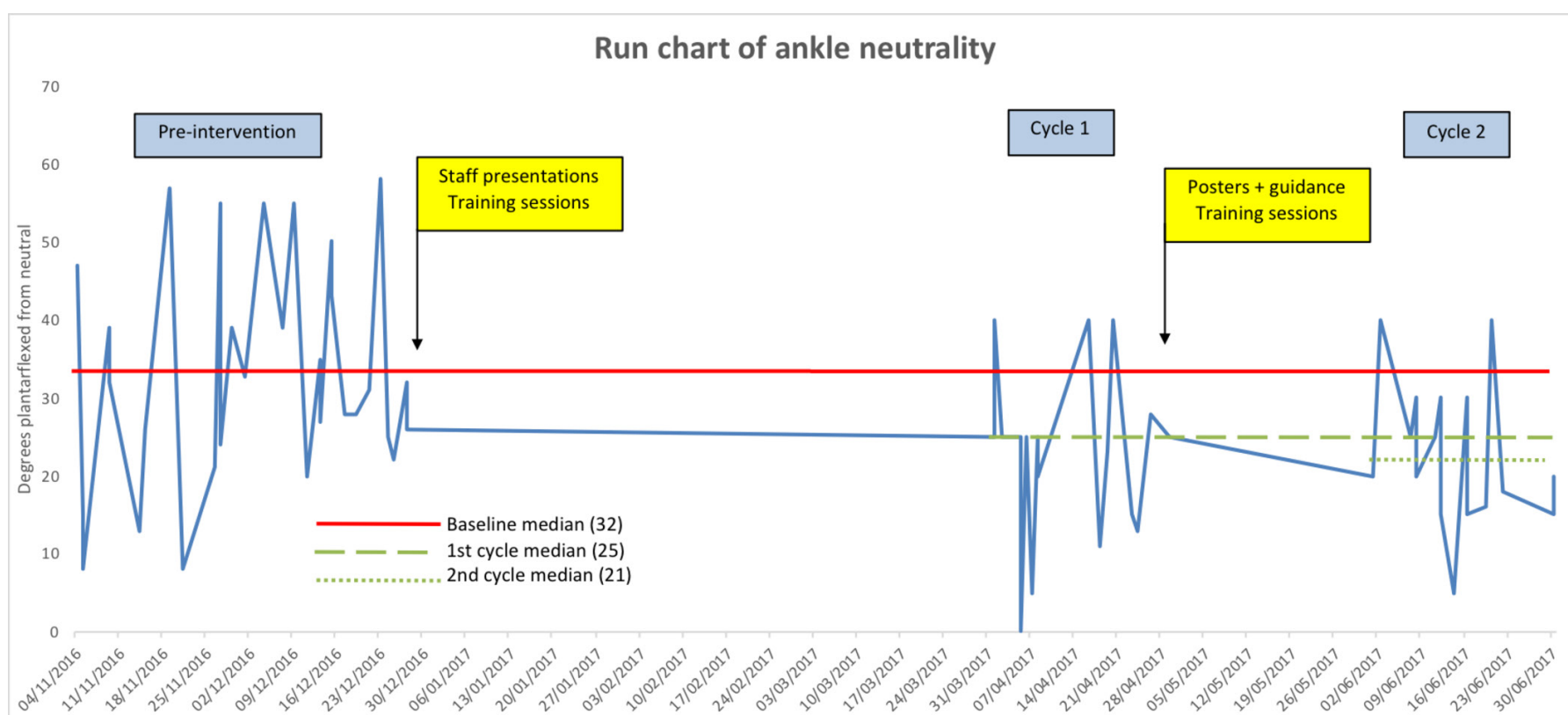

Figure 5 Run chart of ankle neutrality over time.

measurement of $32^{\circ} \mathrm{PF}$ to $25^{\circ} \mathrm{PF}$ ( $\mathrm{p}=0.021 ; 95 \%$ CI 1.63 to 18.59). The proportion of malreduced ankles had fallen from $31 \%(9 / 29)$ to $12 \%(2 / 17)(\mathrm{p}=0.304)$. The proportion undergoing reapplication fell from $21 \%(6 / 29)$ to $0 \%(0 / 17) \quad(\mathrm{p}=0.161)$.

During the second cycle, a further 16 cases were analysed. Median ankle neutrality was $21^{\circ} \mathrm{PF}(\mathrm{p}=0.02 ; 95 \% \mathrm{CI}$ 1.65 to 18.37$)$. The proportion of malreduced ankles was $6 \%(1 / 16) \quad(p=0.148)$. The proportion undergoing reapplication was $12 \%(2 / 16) \quad(\mathrm{p}=0.701)$. The small sample size means the reduction in numbers of reapplications and malreductions are not statistically significant $(\mathrm{p}>0.05)$.

The run chart demonstrates the overall improvement in ankle neutrality over our study period (figure 5), in comparison to the baseline median. The run chart shows shift in data points after both PDSA cycles (six or more consecutive points below the median), although there are no trending consecutive points.

\section{Lessons and limitations}

While there was a clear consensus among senior orthopaedic staff and technicians that below-knee plaster casts were being applied incorrectly, it was challenging to quantify or qualify this in an objective, reproducible and measurable way. Although ankle neutrality and fracture reduction are key components of correct plaster application, other features such as comfort, fit, durability also affect 'quality' of plaster cast. Shortcomings in these areas may too mean a cast must be reapplied.

As expected, it was challenging coordinating improvement between different hospital departments and between disciplines. The nature of the roles and level of training within each department varied, as did the proportion of agency and shift workers. Ensuring senior representatives from each department were kept up to date allowed distribution of information and training could be individualised.

Furthermore, it was not possible to measure the effect of each intervention individually due to our study design. The early effect of the training programme was likely to have been low, but increase as time goes on and more staff are trained. In retrospect, collecting data throughout the entire study period rather than during three separate period may have allowed us to see the effect of interventions over time more accurately.

Lastly, sample sizes were not large enough to demonstrate a significant improvement in the proportion of casts needing reapplication or ankles malreduced. Continued monitoring of performance over time may allow this.

\section{CONCLUSIONS}

This project demonstrated in a measurable and reproducible way that below-knee plaster casts were being applied incorrectly, resulting in unnecessary reapplications that affected patients and put pressure on resources. We implemented a series of interventions including additional training and clinical guidance that have resulted in a sustained improvement in belowknee plaster cast quality. We believe the results of this project justify continuation of the training programme and suggest further study into other commonly applied casts would be worthwhile.

Contributors We would like to acknowledge the contribution of Mr Barry Tedder, orthopaedic practitioner, in organising the plaster training sessions.

Funding This research received no specific grant from any funding agency in the public, commercial or not-for-profit sectors. 
Competing interests None declared.

Provenance and peer review Not commissioned; externally peer reviewed.

Open Access This is an Open Access article distributed in accordance with the Creative Commons Attribution Non Commercial (CC BY-NC 4.0) license, which permits others to distribute, remix, adapt, build upon this work non-commercially, and license their derivative works on different terms, provided the original work is properly cited and the use is non-commercial. See: http://creativecommons.org/ licenses/by-nc/4.0/

(C) Published by the BMJ Publishing Group Limited. For permission to use (where not already granted under a licence) please go to http://www.bmj.com/company/ products-services/rights-and-licensing/

\section{REFERENCES}

1. van Staa TP, Dennison EM, Leufkens HG, et al. Epidemiology of fractures in England and Wales. Bone 2001;29:517-22.

2. Miles S, Williams M. British Orthopaedic Association National Casting Standards, 2015.

3. Bakody E. Orthopaedic plaster casting: nurse and patient education. Nurs Stand 2009;23:49-57.

4. Jayaraman S, Haque S, Ellis D. Audit on adequacy of back-slab application for ankle fracture. Online J Clin Audits 2016.

5. Keene DJ, Mistry D, Nam J, et al. The Ankle Injury Management (AIM) trial: a pragmatic, multicentre, equivalence randomised controlled trial and economic evaluation comparing close contact casting with open surgical reduction and internal fixation in the treatment of unstable ankle fractures in patients aged over 60 years. Health Technol Assess 2016;20:1-158. 